\title{
TELEMETRIC MEASUREMENT OF CORE TEMPERATURE IN PHARMACOLOGICAL RESEARCH: VALIDITY AND RELIABILITY
}

\author{
STEVEN C. DILSAVER, MARK J. MAJCHRZAK, and NORMAN E. ALESSI \\ Department of Psychiatry, University of Michigan, \\ Ann Arbor, Michigan, U.S.A.
}

(Final form, July 1989)

\begin{abstract}
Dilsaver, Steven C., Mark J. Majchrzak, and Norman E. Alessi. Telemetric Measurement of Core Temperature in Pharmacological Research: Validity and Reliability. Prog. Neuro-Psychopharmacol. \& Biol. Psychol., 1990, 14:591-596

1. The authors present data establishing the reliability and validity of a method for telemetrically measuring core temperature.

2. The method is designed to be of particular utility to psychobiological researchers.

Keywords: telemetry, temperature

Abbreviations: intraperitoneally (ip), minute (min)
\end{abstract}

\section{Introduction}

Regulation of core temperature is sensitive to many psychobiological manipulations (Dilsaver et al, 1986, 1987; Dilsaver and Alessi, 1987; Dilsaver, 1990). The purpose of this article is to demonstrate the reliability and validity of a biotelemetric method of measuring core temperature in laboratory animals. This method is designed to be of utility in psychobiological research.

\section{Material and Methods}

\section{Animals}

Five adult, male Sprague-Dawley rats (mean weight \pm SEM $=359.6 \pm$ $12.6 \mathrm{~g})$ were used in this study.

\footnotetext{
${ }^{1}$ Psychopharmacology Program, Department of Psychiatry, Neuroscience Program, The ohio state University, Columbus, Ohio, U.S.A.
} 


\section{Drugs}

clonidine is an $\alpha_{2}$-adrenergic agonist. It preferentially acts at presynaptic auto receptor sites at the doses used in the study reported here.

\section{Apparatus}

The Model VM Mini-Mitter (Mini-Mitter Co, sunriver, $O R$ ) is a biotelemetric thermosensor which emits Hertzian waves, detectable with a standard AM receiver, at a rate directly proportional to temperature.

\section{Calibration of Instruments}

Ten (10) Model VM Mini-Mitters were calibrated by measuring their emission rates in a Model 50 Precision water bath set for $34^{\circ} \mathrm{C}, 35^{\circ} \mathrm{C}$, $36^{\circ} \mathrm{C}, 37^{\circ} \mathrm{C}$, and $38^{\circ} \mathrm{C}$. Each investigator measured the time to emit 10 sounds using a digital display stopwatch (Fisher scientific, Model 14649-5) until they obtained 4 measurements within 0.04 seconds of one another. These measurements were then averaged. This yielded 5 pairs of time ("X" variable) and temperature ("Y" variable). Two linear regression equations were calculated. The first equation was based on the emission rate of the instruments at $34^{\circ} \mathrm{C}, 36^{\circ} \mathrm{C}$, and $38^{\circ} \mathrm{C}$. The second set of equations was based on their emission rates at $34^{\circ} \mathrm{C}$, $35^{\circ} \mathrm{C}, 36^{\circ} \mathrm{C}, 37^{\circ} \mathrm{C}$, and $38^{\circ} \mathrm{C}$. Table 1 lists the regression equations based on the emission profiles of each instrument at both 3 and 5 temperatures. The slopes of the regression equations are directly proportional to change in temperature per unit time. The slopes are statistically indistinguishable for all 10 instruments based on calibration using both 3 and 5 temperature points. This was determined by overlap of the $95 \%$ confldence intervals for each slope. Mini Mitter Implantation and Experimental Procedure

Mini-Mitters were surgically implanted into the peritoneal cavity of 5 adult, male Sprague Dawley rats (mean weight \pm SEM $=359.6 \pm$ 12.6). The animals were allowed 5 days to recover before conducting the experiment. Two investigators (Dilsaver and Majchrzak) measured the time to emit 10 sounds prior to the injection of clonidine $\mathrm{HCl}$, $0.10 \mathrm{mg} / \mathrm{kg}$ ip. This provided the baseline core temperature for each animal. Core temperature (time to emit 10 sounds) was measured every 5 minutes for 120 minutes following the injection of clonidine. change in core temperature relative to baseline was calculated by 
subtracting temperature at baseline from temperature at each of the 24 time points.

\section{Statistical Analysis}

Data were analyzed using the Wilcoxan sign Rank Test for matched pairs and student's paired t-test. All measures of variance in the text refer to the standard error of the mean (SEM).

\section{Results}

Results of Experiment Based on the Calibration of Mini-Mitters Using 5 Temperatures: The mean decrease in core temperature over the course of the experiment as measured by Majchrzak and Dilsaver were $-1.28 \pm$ 0.21 and $-1.22 \pm 0.22$ (mean $\pm S E M$ ), respectively. These do not differ ( $p=0.57, t=0.61, \mathrm{df}=4$, paired $t$-test).

Results of Experiment Based on the Calibration of Mini-Mitters Using 3 Temperatures: Majchrzak and Dilsaver obtained mean decreases in core temperature of $-1.26 \pm 0.21$ and $-1.24 \pm 0.23^{\circ} \mathrm{C}$, respectively, using regression equations calibrated at 3 temperatures $\left(34^{\circ} \mathrm{C}, 36^{\circ} \mathrm{C}\right.$, an $\left.38^{\circ} \mathrm{C}\right)$. These means do not differ $(p=0.19, t=0.86, d f=4$, paired $t$-test).

Results of Experiment Based on the Calibration of Mini-Mitters Using 3 and 5 Temperatures: Majchrzak obtained a mean decrease of $-1.26 \pm$ $0.20^{\circ} \mathrm{C}$ using a regression equation calibrated to 3 temperatures and Dilsaver a mean reduction of $-1.22 \pm 0.22^{\circ} \mathrm{C}$ using a regression equation calibrated to 5 temperatures. These did not differ (p=0.72, $t=0.39$, paired $t$-test). Majchrzak obtained a mean decrease of -1.28 $\pm 0.21^{\circ} \mathrm{C}$ using a regression equation calibrated to 5 temperatures and Dilsaver a mean reduction in core temperature of $-1.24 \pm 0.23^{\circ} \mathrm{C}$ using the regression equation calibrated to 3 temperatures. These did not differ ( $p=0.72, t=0.39$, paired $t$-test).

Internal consistency of Investigators: SCD obtained mean decreases in core temperature of $-1.24 \pm 0.23$ and $-1.22 \pm 0.22^{\circ} \mathrm{C}$ using regression equations calibrated to 3 and 5 temperatures, respectively $(p=0.37$, $t=1.0$, paired $t$-test). Majchrzak obtained mean decreases in core temperature of $-1.26 \pm 0.20$ and $-1.28 \pm 0.21^{\circ} \mathrm{C}$ using regression equations calibrated to 3 and 5 points, respectively. These did not differ ( $p=0.37, t=1.0$, paired $t$-test). 


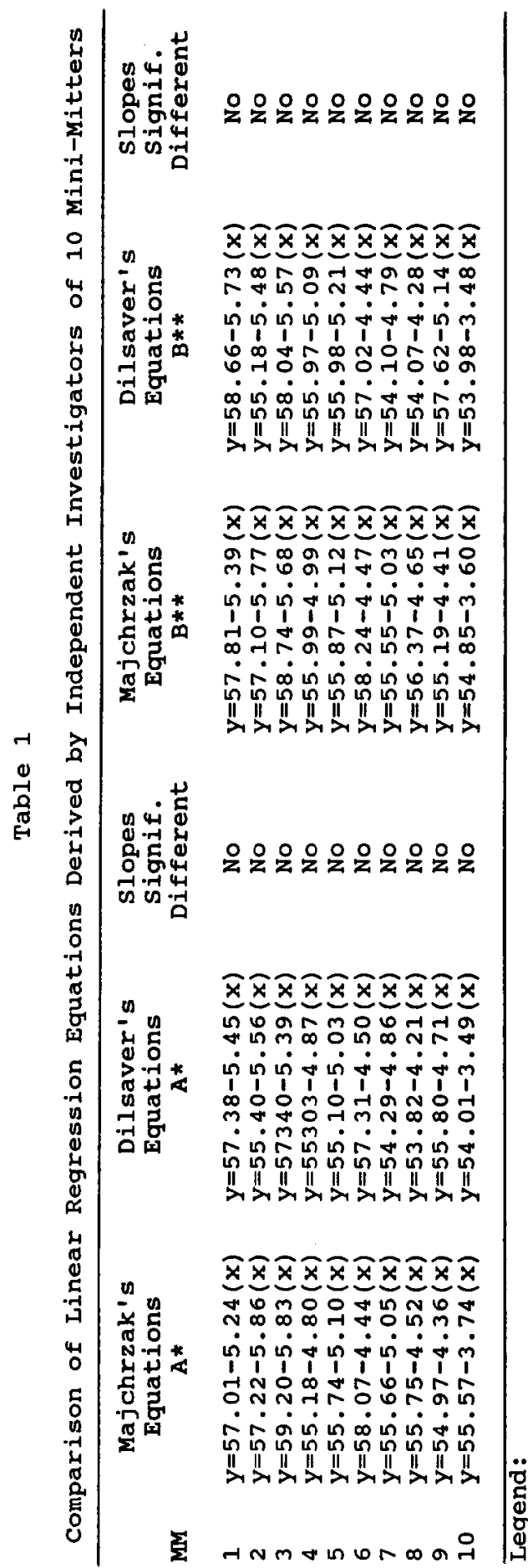

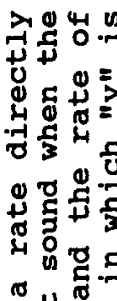

苧范

的范苏

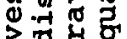

$(0)$

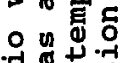

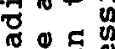

म

气ी ญू

牙恶

తీ용.

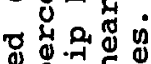

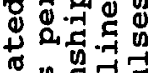

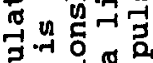

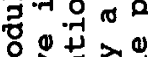

韦茜市男

0 吊出

ปี่

H需㝴

目出 设

员导入皆

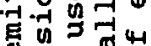

(1) ถึ

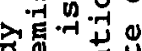

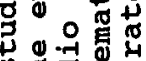

起昰 的

品

क्ष

$4+{ }^{2}=$

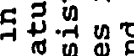

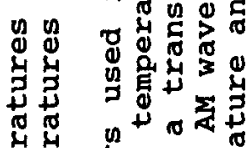

赵

号员

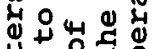

出为山贯

n $\mathrm{m}$ iั $50+$

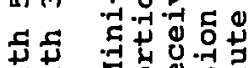

o d

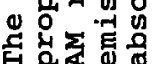

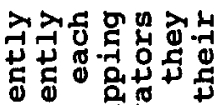

궁

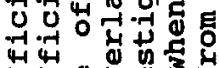

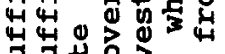

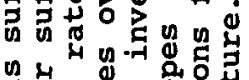

- $\begin{gathered}n \\ \text { म }\end{gathered}$

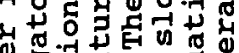

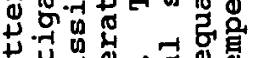

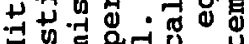

ए

-

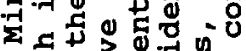

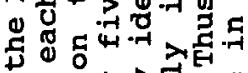

$4>A$

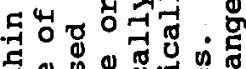

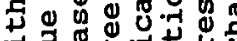

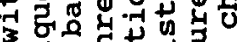

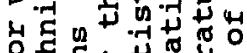

论

c d

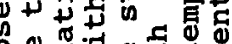

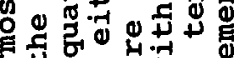

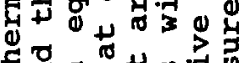

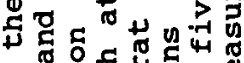

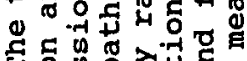

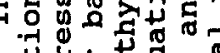

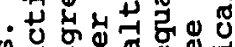

n

吕山西焉

出 的出 0 \%

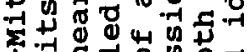

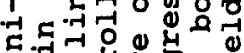

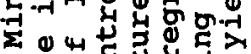

○直 0 ठ

ช.

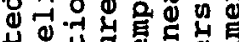

廿

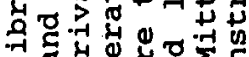

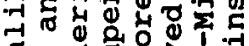

ช ठ ठ

ñ

웜

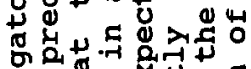
क्ष ए g马

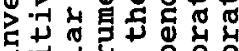

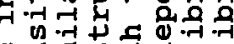

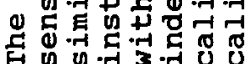




\section{Discussion}

This study demonstrates that independent investigators can obtain statistically equivalent calibrations of the Model VM Mini-Mitter by measuring the emission profile of the instruments at 3 or 5 temperatures. Further, it was possible to obtain statistically indistinguishable results by measuring the time required to emit 10 sounds every 5 minutes in an experiment in which rats were challenged with clonidine $\mathrm{HCl}, 0.10 \mathrm{mg} / \mathrm{kg}$ ip. Finally, calibration of the devices based on the consideration of 3 and 5 points yielded identical results.

others use the Model VM Mini-Mitter to conduct physiological studies. The authors adapted the method to render it useful in assessing pharmacological effects on core temperature. These experiments require frequent measurements in large numbers of animals. In order to carry out these studies, it is necessary to measure the time to emit 10 rather than 50 sounds, as has been the practice of physiologists (Tocco-Bradley et al, 1985). This study indicates that it is possible to obtain useful and reliable data by measuring the time required to emit 10 sounds. Consequently, the Model VM MiniMitter can be employed in psychobiological experiments requiring the measurement of core temperature in large numbers of animals at 5- to 10-min intervals.

\section{Conclusions}

The authors demonstrated that two independent investigators (Dilsaver and Majchrzak) can reliably calibrate these instruments by measuring their emission rates in a temperature controlled water bath at $3\left(34^{\circ} \mathrm{C}, 36^{\circ} \mathrm{C}\right.$, and $\left.38^{\circ} \mathrm{C}\right)$ and $5\left(34^{\circ} \mathrm{C}, 35^{\circ} \mathrm{C}, 36^{\circ} \mathrm{C}, 37^{\circ} \mathrm{C}, 38^{\circ} \mathrm{C}\right)$ temperatures. Also the authors demonstrated that the two investigators obtain statistically identical results using instruments calibrated to both 3 and 5 points, in an experiment in which the thermic response to clonidine, $0.10 \mathrm{mg} / \mathrm{kg} \mathrm{ip}$, is measured in rats.

\section{Acknowledgements}

This study was supported in part by Physician scientist career Development Award, Grant \#SRC1K11 MH00553-02 (Muscarinic Receptor Abnormalities in Affective Illness) awarded by the National institute of Mental Health and NIH2507RR05383-25. 


\section{References}

DILSAVER, S.C. (1990) Neurobiologic effects of bright light. Brain Research Reviews, in press.

DILSAVER, S.C., and ALESSI, N.E. (1987) Chronic inescapable footshock produces cholinergic system supersensitivity. Biological Psychiatry 22: 914-918.

DILSAVER, S.C., SNIDER, R.M., and ALESSI, N.E. (1986) stress induces supersensitivity of a cholinergic system in rats. Biological Psychiatry 21: 1093-1096.

DILSAVER, S.C., SNIDER, R.M., and ALESSI, N.E. (1987) Amitriptyline supersensitizes a central cholinergic mechanism. Biological Psychiatry 22: 495-507.

TOCCO-BRADLEY, R., KLUGER, M. J. and KAUFFMAN, C. A. (1985) Ef fect of age on fever: An acute phase response of rats to endotoxin and Salmonella typhimurium. Infect. Immun. 47: 106-111.

Inquiries and reprint requests should be addressed to:

Steven C. Dilsaver, M.D.

Psychopharmacology Program

Department of Psychiatry

The ohio state University

473 west 12 th Avenue

Columbus, Ohio 43210-1228 